Pacific Journal of Mathematics

POSITIVE HOLOMORPHIC DIFFERENTIALS ON KLEIN 


\title{
POSITIVE HOLOMORPHIC DIFFERENTIALS ON KLEIN SURFACES
}

\author{
Newcomb Greenleaf and Walter Read
}

Let $\mathfrak{X}$ be a compact Klein surface with boundary $\partial X$, and let $\mathcal{O}$ be an orientation of $\partial X$. We conjecture that there is a holomorphic differential which is positive on $\mathcal{O}$ if and only if $O$ is not induced by an orientation of $X$, and we prove this when $\mathfrak{X}$ is elliptic or hyperelliptic.

Let $\mathfrak{X}$ be a Klein surface, with underlying topological space $X$, and let $\eta$ be a meromorphic differential on $\mathfrak{X}$ (for basic definitions and results see [1], [2]). If $\mathfrak{g} \in E(\mathfrak{X})$ is a nonconstant meromorphic function, then there is a unique $f \in E(\mathfrak{X})$ such that $\eta=f \cdot d g$.

Let $B$ be an oriented component of $\partial X$, and let $-B$ be the same component with the opposite orientation. For $x \in B$ choose a local parameter $\mathfrak{g} \in E(\mathfrak{X})$ such that $g$ is increasing on $B$ near $x$. We say that $\eta$ is positive on $B$ at $x$ if $\eta=f \cdot d \mathfrak{g}$ with $0<\mathrm{f}(x)<\infty$, and that $\eta$ is positive on $B$ if it is positive at all $x \in B$. It is easily checked that this definition does not depend on the choice of local parameters. Further $\eta$ is positive on $B$ or $-B$ if and only if it has no zeros or poles on $B$, and if $\eta$ is positive on $B$, then $-\eta$ is positive on $-B$.

By an orientation $\mathcal{O}$ of $\partial X$ we mean an orientation of each component of $\partial X$. If $\partial X$ has $r$ components, then it has $2^{r}$ orientations. If $X$ is orientable, then two of these are induced by the two possible orientations of $X$. If $\eta$ is positive on each component of $\mathcal{O}$, we will say that it is positive on $\mathcal{O}$, and that $\mathscr{O}$ has a positive differential.

In this note we investigate the following question: if $\mathfrak{X}$ is a compact Klein surface and $\sigma$ is an orientation of $\partial X$, does $\sigma$ have a positive holomorphic differential. Our first result is in the negative direction.

THEOREM 1. Let $\mathfrak{X}$ be a compact orientable Klein surface, and let $O$ be an orientation of $\partial X$ induced by an orientation of $X$. Then O has no positive holomorphic differentials.

Proof. Let $\mathfrak{X}_{1}$ be the analytic structure which is contained in the dianalytic structure $\mathfrak{X}$ and which corresponds to the orientation of $\mathfrak{X}$ which induces $O$. If $\eta$ is a holomorphic differential on $X$, we can as well regard it as a differential on $\mathfrak{X}_{1}$, and we can then apply the Cauchy integral theorem to obtain $\int_{0} \eta=0$. If $\eta$ were positive on $\mathcal{O}$, this integral would be strictly positive. Note that this proof 
extends to meromorphic differentials of the second kind which have no poles on $\partial X$.

We conjecture that if an orientation $O$ is not induced by an orientation of $X$, then it has a positive holomorphic differential, but we can so far prove this only in the cases $\mathfrak{X}$ elliptic or $\mathfrak{X}$ hyperelliptic (i.e., when $\mathfrak{X}$ can be represented as a double cover of the compactified upper half plane $\mathfrak{D})$.

THEOREM 2. Let $\mathfrak{X}$ be an elliptic or hyperelliptic Klein surface and let $O$ be an orientation of $\partial X$ not induced by any orientation of $X$. Then $\bigcirc$ has a positive holomorphic differential.

Proof. Let $\mathfrak{X}$ be an elliptic or hyperelliptic with $r \geqq 1$ boundary components. We can find meromorphic functions $f, g$ which generate $E(\mathfrak{X})$ over the reals, with $\mathrm{f}^{2}=H(\mathfrak{g})$, where $H$ is a real polynomial of degree $n$ without multiple factors. Then the mapping associated with $\mathfrak{g}$ represents $\mathfrak{X}$ as a double cover of $\mathfrak{D}$, which is ramified at the zeros of $H$, and also at $\infty$ if $n$ is odd. If $H$ has no real zeros, then $r=1$ or $r=2$, depending on whether $n / 2$, the number of ramified points in the interior of $\mathfrak{D}$, is odd or even. If $H$ has $m \geqq 1$ real zeros, then $r=[(m+1) / 2]$.

The genus of $\mathfrak{X}$ is $\gamma=[(n-1) / 1]$, and the differentials $\{d \mathfrak{g} / \mathfrak{f}, \mathfrak{g} \cdot d \mathfrak{g} / \mathfrak{f}$, $\left.\cdots, \mathfrak{g}^{r-1} \cdot d \mathfrak{g} / \mathfrak{f}\right\}$ form a basis over $R$ for the space of holomorphic differentials on $\mathfrak{X}$ (see [3], p. 293). $\mathfrak{X}$ may have two real points, one real point, or one complex point at infinity. The differential $d \mathfrak{g} / \mathfrak{f}$ has all of its zeros at infinity. In the first case it has zeros of order $\gamma-1$ at each such point, in the second a zero of order $2 \gamma-2$, and in the third a zero of order $\gamma-1$.

Assume now that $H$ has no real zeros. Then $X$ is orientable. If $r=1$, then every orientation of $\partial X$ comes from an orientation of $X$, so there is nothing to prove. If $r=2$, then $\gamma-1=n / 2-2$ is even. The differential $\left(\mathfrak{g}^{\gamma-1}+1\right) \cdot d \mathfrak{g} / \mathfrak{f}$ has no zeros on $\partial X$ and hence is positive with respect to some orientation $\mathcal{O}$, and its negative is positive on $-\infty$.

Now assume that $H$ has $m \geqq 1$ real zeros. By choosing, if necessary, a new generator for $R(\mathfrak{g})$, we may assume that $\mathfrak{X}$ has a single complex point at infinity. Then $H$ has $2 r$ real zeros, and $n=2(r+s)$, where $s$ is the number of irreducible quadratic factors of $H$. Let the real zeros of $H$, in increasing order, be $a_{1}, b_{1}, \cdots, a_{r}, b_{r}$, and pick $c_{j}$ between $b_{j}$ and $a_{j+1}, j=1, \cdots, r-1$. Then the components of $\partial X$ lie over the intervals $\left[a_{j}, b_{j}\right], j=1, \cdots, r$. Let $J \subset\{1, \cdots, r-1\}$ be any set of cardinality at most $\gamma-1$, and set 


$$
\eta_{J}=\prod_{j \in J}\left(g-c_{j}\right) \cdot d \mathfrak{g} / \mathfrak{f}
$$

Each of the differentials $\pm \eta_{J}$ is positive with respect to a different orientation of $\partial X$. Hence for $\gamma \geqq r$ we obtain positive differentials for all $2^{r}$ possible orientations of $\partial X$, and the theorem is proved. So assume that $\gamma<r$. Since $r+1=n / 2=r+s$, we must have $s=0$ and $\gamma=r-1$. Because $s=0, X$ is orientable, and because $\gamma=r-1$ we can use all subsets $J$ except $J=\{1, \cdots, r-1\}$. We have thus obtained positive differentials for $2^{r}-2$ different orientations of $\partial X$, and have completed the proof of the theorem.

\section{REFERENCES}

1. N. Alling and N. Greenleaf, Klein surfaces and real algebraic function fields, Bell. Amer. Math. Soc. 75 (1969), 869-872.

2. N. Alling and N. Greenleaf, Klein surfaces, Springer Lecture Notes in Mathematics (to appear)

3. G. Springer, Introduction to Riemann surfaces, Reading, Mass., 1957.

Received August 5, 1969. The first author was partially supported by a National Science Foundation research grant, and the second author was supported by a National Defense Education Act fellowship.

The University of California, Berkeley

THE UNIVERSITY OF ROCHESTER 



\title{
PACIFIC JOURNAL OF MATHEMATICS
}

\author{
EDITORS
}

H. SAMELSON

Stanford University

Stanford, California 94305

J. DugunduI

Department of Mathematics

University of Southern California

Los Angeles, California 90007

RICHARD PIERCE

University of Washington

BASIL GORDON*

University of California

Seattle, Washington 98105

Los Angeles, California 90024

\section{ASSOCIATE EDITORS}

E. F. BeCKenbaCh

B. H. NeumanN

F. WOLF

K. YosHIDA

\section{SUPPORTING INSTITUTIONS}

\author{
UNIVERSITY OF BRITISH COLUMBIA \\ CALIFORNIA INSTITUTE OF TECHNOLOGY \\ UNIVERSITY OF CALIFORNIA \\ MONTANA STATE UNIVERSITY \\ UNIVERSITY OF NEVADA \\ NEW MEXICO STATE UNIVERSITY \\ OREGON STATE UNIVERSITY \\ UNIVERSITY OF OREGON \\ OSAKA UNIVERSITY \\ UNIVERSITY OF SOUTHERN CALIFORNIA
}

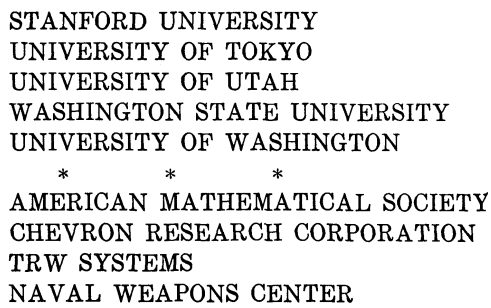

The Supporting Institutions listed above contribute to the cost of publication of this Journal, but they are not owners or publishers and have no responsibility for its content or policies.

Mathematical papers intended for publication in the Pacific Journal of Mathematics should be in typed form or offset-reproduced, double spaced with large margins. Underline Greek letters in red, German in green, and script in blue. The first paragraph or two must be capable of being used separately as a synopsis of the entire paper. It should not contain references to the bibliography. Manuscripts, in duplicate if possible, may be sent to any one of the four editors. Please classify according to the scheme of Math. Rev. 36, 1539-1546. All other communications to the editors should be addressed to the managing editor, Richard Arens, University of California, Los Angeles, California, 90024.

50 reprints are provided free for each article; additional copies may be obtained at cost in multiples of 50 .

The Pacific Journal of Mathematics is published monthly. Effective with Volume 16 the price per volume (3 numbers) is $\$ 8.00$; single issues, $\$ 3.00$. Special price for current issues to individual faculty members of supporting institutions and to individual members of the American Mathematical Society: $\$ 4.00$ per volume; single issues $\$ 1.50$. Back numbers are available.

Subscriptions, orders for back numbers, and changes of address should be sent to Pacific Journal of Mathematics, 103 Highland Boulevard, Berkeley, California, 94708.

PUBLISHED BY PACIFIC JOURNAL OF MATHEMATICS, A NON-PROFIT CORPORATION

Printed at Kokusai Bunken Insatsusha (International Academic Printing Co., Ltd.), 7-17, Fujimi 2-chome, Chiyoda-ku, Tokyo, Japan.

* Acting Managing Editor. 


\section{Pacific Journal of Mathematics}

\section{Vol. 32, No. 3 \\ March, 1970}

Shair Ahmad, Dynamical systems of characteristic $0^{+} \ldots \ldots \ldots \ldots \ldots$

Charles A. Akemann and Bernard Russo, Geometry of the unit sphere of a $C^{*}$-algebra and its dual............................ 575

Philip Bacon, The compactness of countably compact spaces ......... 587

Richard Blaine Barrar and Henry Loeb, On the continuity of the nonlinear Tschebyscheff operator ............................ 593

L. Carlitz, Factorization of a special polynomial over a finite field ....... 603

Joe Ebeling Cude, Compact integral domains .................... 615

Frank Rimi DeMeyer, On automorphisms of separable algebras. II . . . . . 621

James B. Derr, Generalized Sylow tower groups .................. 633

Raouf Doss, Some inclusions in multipliers ................... 643

Mary Rodriguez Embry, The numerical range of an operator........... 647

John Froese, Domain-perturbed problems for ordinary linear differential

operators..................................... 651

Zdeněk Frolík, Absolute Borel and Souslin sets ..................... 663

Ronald Owen Fulp, Tensor and torsion products of semigroups .......... 685

George Grätzer and J. Płonka, On the number of polynomials of an

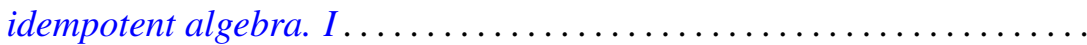

Newcomb Greenleaf and Walter Read, Positive holomorphic differentials on

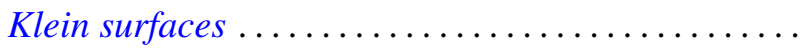

John Willard Heidel, Uniqueness, continuation, and nonoscillation for a second order nonlinear differential equation ................. 715

Leon A. Henkin, Extending Boolean operations................... 723

R. Hirshon, On hopfian groups .......................... 753

Melvin Hochster, Totally integrally closed rings and extremal spaces ..... 767

R. Mohanty and B. K. Ray, On the convergence of a trigonometric integral ..................................

Michael Rich, On a class of nodal algebras .................... 787

Emile B. Roth, Conjugate space representations of Banach spaces ........ 793

Rolf Schneider, On the projections of a convex polytope .............. 799

Bertram Manuel Schreiber, On the coset ring and strong Ditkin sets ...... 805

Edgar Lee Stout, Some remarks on varieties in polydiscs and bounded

holomorphic functions .........................

James Edward Ward, Two-groups and Jordan algebras . 